\title{
Massive bowel resection upregulates the intestinal mRNA expression levels of cellular retinol-binding protein II and apolipoprotein A-IV and alters the intestinal vitamin A status in rats
}

\author{
TAKU HEBIGUCHI ${ }^{1}$, YOSHIHIRO MEZAKI $^{2}$, MAYAKO MORII $^{1}$, RYO WATANABE $^{1}$, \\ KIWAMU YOSHIKAWA ${ }^{2}$, MITSUTAKA MIURA ${ }^{2}$, KATSUYUKI IMAI ${ }^{2}$, \\ HARUKI SENOO $^{2}$ and HIROAKI YOSHINO ${ }^{1}$ \\ Departments of ${ }^{1}$ Pediatric Surgery and ${ }^{2}$ Cell Biology and Morphology, \\ Akita University Graduate School of Medicine, Akita 010-8543, Japan
}

Received August 6, 2014; Accepted December 24, 2014

DOI: $10.3892 /$ ijmm.2015.2066

\begin{abstract}
Short bowel (SB) syndrome causes the malabsorption of various nutrients. Among these, vitamin A is important for a number of physiological activities. Vitamin A is absorbed by epithelial cells of the small intestine and is discharged into the lymphatic vessels as a component of chylomicrons and is delivered to the liver. In the present study, we used a rat model of SB syndrome in order to assess its effects on the expression of genes associated with the absorption, transport and metabolism of vitamin $\mathrm{A}$. In the rats with $\mathrm{SB}$, the intestinal mRNA expression levels of cellular retinol-binding protein II (CRBP II, gene symbol Rbp2) and apolipoprotein A-IV (gene symbol Apoa4) were higher than those in the sham-operated rats, as shown by RT-qPCR. Immunohistochemical analysis revealed that absorptive epithelial cells stained positive for both CRBP II and lecithin retinol acyltransferase, which are both required for the effective esterification of vitamin A. In the rats with $\mathrm{SB}$, the retinol content in the ileum and the retinyl ester content in the jejunum were lower than those in the sham-operated rats, as shown by quantitative analysis of retinol and retinyl esters by high performance liquid chromatography. These results suggest that the elevated mRNA expression levels
\end{abstract}

Correspondence to: Dr Yoshihiro Mezaki, Department of Cell Biology and Morphology, Akita University Graduate School of Medicine, 1-1-1 Hondo, Akita 010-8543, Japan

E-mail: mezaki@gipc.akita-u.ac.jp

Professor Hiroaki Yoshino, Department of Pediatric Surgery, Akita University Graduate School of Medicine, 1-1-1 Hondo, Akita 010-8543, Japan

E-mail: hiroyosi@med.akita-u.ac.jp

Key words: short bowel syndrome, vitamin A, cellular retinolbinding protein II, lecithin retinol acyltransferase, apolipoprotein A, intestinal adaptation of Rbp2 and Apoa4 in the rats with SB contribute to the effective esterification and transport of vitamin A.

\section{Introduction}

Short bowel (SB) syndrome occurs as a consequence of malabsorption from an intestinal surface area insufficient to maintain growth and a normal nutritional status $(1,2)$. Intestinal adaptation is a well-known phenomenon that increases the absorptive capacity following surgical resection of the small intestine. The most prominent feature of intestinal adaptation is the proliferation of intestinal cells that increases crypt depth and enlarges the length and width of the villi (3). It is known that micronutrients affect several aspects of intestinal adaptation. Wang et al (4) reported that intestinal adaptation was facilitated by retinoic acid, an active form of vitamin A. The authors demonstrated that the intravenous administration of retinoic acid exerted trophic effects in rats with SB by inhibiting apoptosis and stimulating crypt cell proliferation (4).

Vitamin A is a fat-soluble vitamin required for a number of physiological activities. Retinyl esters (REs), animal-derived forms of vitamin A, are hydrolyzed into retinol before entering the absorptive epithelial cells. By contrast, $\beta$-carotene, a vegetable-derived form of vitamin $A$, is converted into retinal after entering the absorptive epithelial cells and is then reduced to retinol within the cells (5). The retinol thus produced binds to cellular retinol-binding protein II (CRBP II, gene symbol $R b p 2$ ) in absorptive epithelial cells, forming a retinol-CRBP II complex. This complex is esterified to REs by lecithin retinol acyltransferase (LRAT, gene symbol Lrat). REs are then discharged basolaterally into the lymphatic vessels as a component of chylomicrons and are delivered to the liver through the general circulation (6). In hepatocytes, REs are hydrolyzed into retinol and complexed with retinol-binding protein (RBP, gene symbol $R b p 4$ ). The retinol-RBP complex is transferred to hepatic stellate cells (HSCs) where the retinol binds to CRBP I (gene symbol Rbpl) and is again esterified to REs by LRAT for storage $(7,8)$. 
CRBP I and II are members of the retinoid-binding protein family (9) which constitutes the calycin protein superfamily together with the fatty acid-binding proteins (FABPs) (10). In mammals, CRBP I is expressed ubiquitously $(11,12)$, whereas CRBP II is expressed specifically in the intestine and the fetal liver (13). CRBP II expression increases perinatally, a change that is associated with the growth and differentiation of the intestine (13). CRBP II knockout mice have been shown to be more susceptible to vitamin A deficiency, suggesting that CRBP II plays an important role in vitamin A homeostasis (14). Takase et al (15) reported that jejunal bypass surgery led to a marked increase in the levels of CRBP II in the residual jejunal segment of rats. The upregulation of the $R b p 2$ gene in rats with SB was also reported by Dodson et al (16). It has been demonstrated that the upregulation of the mRNA expression of $R b p 2$ results in the growth of absorptive epithelial cells, presumably through increased vitamin A absorption by those cells (17).

As noted above, vitamin A is thought to be trophic to the bowel, and may therefore be important during adaptation in SB syndrome, and the deficiency of vitamin A may have negative consequences for adaptation. In the present study, we examined the effect of significant bowel resection on vitamin A absorption, transport and metabolism. For this purpose, we used a rat model of SB and analyzed vitamin A-related factors by reverse transcription-quantitative PCR (RT-qPCR), western blot analysis and immunohistochemistry, as well as measurements of vitamin A in tissues and cultured cells.

\section{Materials and methods}

Animals and surgical procedures. Protocols for animal experimentation were approved by the Animal Research Committee, Akita University Graduate School of Medicine, Akita, Japan. All animal experiments adhered to the 'Guidelines for Animal Experimentation' of the University. Male Sprague-Dawley rats (ages ranged from 8 to 11 weeks, 280-480 g body weight) were used in this study. Twelve hours after fasting, each animal was anesthetized by an intraperitoneal injection of pentobarbital. In the sham-operated rats, the gut was simply divided $10 \mathrm{~cm}$ proximal to the ileocecal junction and anastomosed without resecting any part (Fig. 1A). For the induction of SB in the animals, the small bowel was resected from a point $5 \mathrm{~cm}$ distal to the ligament of Treitz to a point $10 \mathrm{~cm}$ proximal to the ileocecal junction, resulting in a $75 \%$ resection of the small intestine. Mesenteric vessels were ligated with sutures, and bowel continuity was restored by end-to-end anastomosis (Fig. 1B, arrow). The rats were fasted for $24 \mathrm{~h}$, but were allowed free access to water. The rats with SB and sham-operated rats were then fed with Elental (Ajinomoto Pharmaceuticals, Tokyo, Japan) according to the manufacturer's instructions. On day 7 , the animals were sacrificed with an intraperitoneal injection of pentobarbital, and the livers and small intestines were excised and immersed in $10 \%$ formalin. For RNA preparation, small sections of the livers and small intestines were quick-frozen in liquid nitrogen and kept frozen at $-85^{\circ} \mathrm{C}$.

A pair of rats underwent surgery for each trial: 1 animal for SB and 1 for the sham operation. From the 19 pairs of rats, 13 rats with SB and 14 sham-operated completed the trial. The jejuna of the sham-operated rats were collected from 8 animals out of the 14 animals that underwent surgery. Over the first 2 days following surgery, both the rats with SB and the sham-operated rats lost weight (Fig. 1C). Afterwards, the sham-operated rats gradually regained weight, whereas the rats with SB continued to lose weight.

$R N A$ extraction and $R T-q P C R$. The frozen rat livers and intestines were dissolved in TRIzol reagent (Life Technologies, Carlsbad, CA, USA) and total RNA was isolated. The cDNAs were synthesized from $5 \mu \mathrm{g}$ of total RNA using SuperScript III Reverse Transcriptase (Life Technologies) using an oligo(dT) $)_{18}$ primer. The quantification of cDNA was carried out using the LightCycler 480 SYBR-Green I Master (Roche Diagnostics, Meylan, France). Transcript amounts were normalized against the glyceraldehyde 3-phosphate dehydrogenase (Gapdh) transcript. The nucleotide sequences used are summarized in Table I.

Organelle fractionation. Small sections of tissue (50-150 mg) were homogenized in $0.5 \mathrm{ml}$ of cell disruption buffer $(0.25 \mathrm{M}$ sucrose, $20 \mathrm{mM}$ HEPES, pH 7.5) using a Polytron CT 2100 homogenizer (Kinematica AG, Littau-Luzern, Switzerland). The samples were further homogenized by 20 strokes using a Dounce tissue grinder (Wheaton, Millville, NJ, USA). The homogenates were centrifuged for $7 \mathrm{~min}$ at $1,100 \mathrm{x}$. The supernatants were further centrifuged at $1,900 \mathrm{x}$ g for $30 \mathrm{~min}$. The pellets were set aside as mitochondrial fractions and the supernatants were again centrifuged at $105,000 \mathrm{x} \mathrm{g}$ for $1 \mathrm{~h}$. The pellets were set aside as microsomal fractions and final supernatants were cytosol fractions. The pelleted organelle fractions were dissolved in $100 \mu \mathrm{l}$ of cell disruption buffer. Protein concentrations in all the organelle fractions were determined using the BCA protein assay reagent (Thermo Scientific, Rockford, IL, USA).

Western blot analysis. A total of $50 \mu \mathrm{g}$ of each organelle fraction was separated by SDS-PAGE and transferred onto PVDF membranes (Atto, Tokyo, Japan). The membranes were incubated with primary antibodies against either CRBP I (1:200 dilution, sc-30106; Santa Cruz Biotechnology, Inc., Santa Cruz, CA, USA), CRBP II (1:10 dilution, HPA035866; Sigma-Aldrich, St. Louis, MO, USA) or LRAT (1:200 dilution; Immuno-Biological Laboratories, Gunma, Japan). A peroxidase-conjugated secondary antibody (1:5,000 dilution, 111-035-003; Jackson ImmunoResearch, West Grove, PA, USA) was applied. Bound antibodies were detected by ECL chemiluminescence (GE Healthcare Life Sciences, Piscataway, NJ, USA) and recorded on X-ray film (Fujifilm, Tokyo, Japan). As the positive controls, whole cell lysates from HEK293T cells transfected with $R b p 1$ or $R b p 2$ plasmids were used.

Immunohistochemistryandhistochemistry.Paraffin-embedded ilea were sectioned at 3- $\mu \mathrm{m}$ intervals. To unmask the antigens, the specimens were boiled in citrate buffer $(0.01 \mathrm{M}, \mathrm{pH} 6.0)$ for $25 \mathrm{~min}$. For the inactivation of endogenous peroxidase activity, the slides were immersed in $1 \% \mathrm{H}_{2} \mathrm{O}_{2}$ for $20 \mathrm{~min}$. The specimens were incubated with either CRBP II antibody (1:10 dilution) or LRAT antibody (1:100 dilution) overnight at $4{ }^{\circ} \mathrm{C}$. The slides were treated with a 1:500 dilution of peroxidaseconjugated secondary antibody and incubated with DAB substrate (Roche Diagnostics). The nuclei were counterstained with Mayer's hematoxylin solution (Wako Pure Chemical, Osaka, Japan). Hematoxylin and eosin (H\&E) staining was also 
Table I. Primers used for RT-qPCR.

\begin{tabular}{lllc}
\hline Gene & \multicolumn{1}{c}{ Forward } & \multicolumn{1}{c}{ Reverse } & Length (bp) \\
\hline Gapdh & ACAGCAACTCCCATTCTTCC & TCCACCACCCTGTTGCTGTA & 118 \\
Rbp 1 & AGGCATAGATGACCGCAAGT & TCATCACCCTCAATCCACTG & 117 \\
R $b p 2$ & GAAACACCCTGGTGTGCGTG & GAACACTTGTCGACACACCT & 122 \\
R $b p 4$ & GTTTCTCGTGACCCCAATG & ACTGTTTCTTGAGGGTCTGC & 139 \\
Lrat & GCGAACACTTTGTGACCTAC & GACAGCTGAAGCAAGACAAC & 119 \\
Apoat & TGAAGGCTGTGGTGCTGA & CCTCCTTGGCATTGTTGC & 126 \\
Apob & CAGCCATAGGCACTGTGAGTC & TGTCCCTCCACTCCATTTTG & 126 \\
Fabpl & TTCTCCGGCAAGTACCAAGT & TTCATGCACGATTTCTGACAC & 126 \\
Fabp 2 & TGATGGCACTTGGAAAGTAGAC & CCTTCCTGTGTGATCGTCAG & 126 \\
\hline
\end{tabular}

Gapdh, glyceraldehyde 3-phosphate dehydrogenase; Rbp1, retinol-binding protein 1; Lrat, lecithin retinol acyltransferase; Apoa4, apolipoprotein A-IV; Apob, apolipoprotein B, Fabp, fatty acid-binding protein.

performed for histological comparisons. The specimens were recorded digitally using the NanoZoomer Digital Pathology system (Hamamatsu Photonics, Hamamatsu, Japan).

Quantitative analysis of retinol and REs by high performance liquid chromatography (HPLC). Small sections of tissue (30-100 mg) were homogenized in $0.5 \mathrm{ml}$ of cell disruption buffer (20 mM Tris-HCl, pH 8.0) using a Polytron CT 2100 homogenizer. Follwoing the addition of $0.5 \mathrm{ml}$ methanol and $1.75 \mathrm{ml}$ dichloromethane, the homogenates were vigorously agitated with a Vortex mixer for $1 \mathrm{~min}$. Subsequently, $0.5 \mathrm{ml}$ of distilled water and $2.75 \mathrm{ml}$ of hexane were added and agitated with a Vortex mixer for $5 \mathrm{sec}$, and the samples were then centrifuged for $5 \mathrm{~min}$ at 3,000 $\mathrm{x} \mathrm{g}$. The supernatants were set aside in a pear-shaped flask. The same procedures were carried out using the lower layer of the centrifuged samples without the addition of water. The dried supernatant was dissolved in $200 \mu \mathrm{l}$ of $\mathrm{N} 1$ (mixture of $125 \mathrm{ml}$ benzene, $25 \mathrm{ml}$ tert-butyl methyl ether, $0.2 \mathrm{ml}$ ethanol and $350 \mathrm{ml}$ hexane) and assessed by HPLC (Elite LaChrom; Hitachi, Tokyo, Japan) with a silica gel column (SL12S03-1506WT; YMC, Kyoto, Japan) for the quantification of retinol. The flow-through fraction containing REs was collected, dried and saponized in $\mathrm{KOH}\left(0.33 \mathrm{M}\right.$ in ethanol) for $30 \mathrm{~min}$ at $40^{\circ} \mathrm{C}$. Subsequently, $1.75 \mathrm{ml}$ of dichloromethane and $2.75 \mathrm{ml}$ of hexane were added to the saponized samples, and mixed for $30 \mathrm{sec}$. Distilled water $(1 \mathrm{ml})$ was added and mixed for $30 \mathrm{sec}$ and centrifuged for $5 \mathrm{~min}$ at 3,000 $\mathrm{x}$ g. The supernatant was set aside in a pearshaped flask. The same procedures were repeated. The retinol contained in the extracts was analyzed by HPLC.

Plasmids. The cDNA for CRBP II (Rbp2) and LRAT (Lrat) was amplified from the isolated rat HSCs by reverse transcription-PCR using primers designed from the reported cDNA sequences (GenBank accession no. NM_012640 for Rbp 2 and GenBank accession no. NM_022280 for Lrat) and inserted into the KpnI and EcoRI sites of pcDNA3.1 (Life Technologies). The primer pairs used for the cloning of $R b p 2$ and Lrat were 5'-GACTGGTACCATGACGAAGGACCAG AATGG-3' and 5'-GGAATTCTCACTTCTTTTTGAACA
CTTGTC-3'; 5'-GACGGTACCATGAAGAACTCAATGC TGGAG-3' and 5'-GACTGGAATTCCTAGCCAGACAT CATCCAC-3', respectively. Forty cycles of PCR were required to amplify the cDNA for Rbp2 from the HSCs. The cloned cDNAs were verified by sequencing.

Transfection. Transfection of the plasmids into HEK293T cells was carried out using Lipofectamine 2000 reagent (Life Technologies). A total of $2 \mu \mathrm{g}$ each of $R b p 2$ and Lrat cDNA was added to a $6-\mathrm{cm}$ dish ( $\mathrm{n}=8$ for each condition). Eighteen hours after transfection, the cells were treated with $10 \mu \mathrm{M}$ retinol (Sigma-Aldrich) in Dulbecco's modified Eagle's medium (DMEM; Life Technologies) supplemented with fetal bovine serum (SAFC Bioscience, Lenexa, KS, USA) for $10 \mathrm{~min}$. The cells were collected, quick-frozen in liquid nitrogen and stored at $-85^{\circ} \mathrm{C}$ until vitamin A quantification by HPLC.

Statistical analysis. Data are expressed as the means \pm standard deviation (SD). The statistical significance of the differences was evaluated by an unpaired Student's t-test for data shown in Figs. 2 and 5, and by ANOVA combined with Tukey's test for data shown in Fig. 6. P-values $<0.05$ were considered to indicate a statistically significant difference.

\section{Results}

Upregulation of Rbp 2 and apolipoprotein A-IV (Apoa4) $m R N A$ epxression in the intestines of rats with $S B$. We examined the mRNA expression levels of genes related to retinoid absorption, transport and metabolism (Fig. 2). Rbpl mRNA was predominantly expressed in the liver and no significant changes were observed in its expression levels between the rats with SB and the sham-operated rats in either the liver or the intestine. The mRNA expression levels of $R b p 4$ in the ilea of rats with $\mathrm{SB}$ and sham-operated rats differed significantly $(\mathrm{P}<0.05)$, although the mRNA expression of $R b p 4$ in the intestines was considerably lower than that in the livers. Rbp 2 mRNA was specifically expressed in the intestines, and the mRNA expression levels of $R b p 2$ in the rats with SB were higher than those in the sham-operated rats in both the jejuna and the ilea 
A

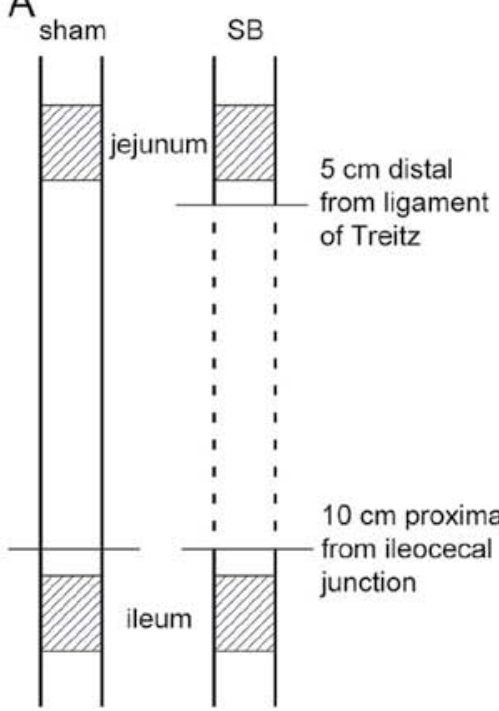

B

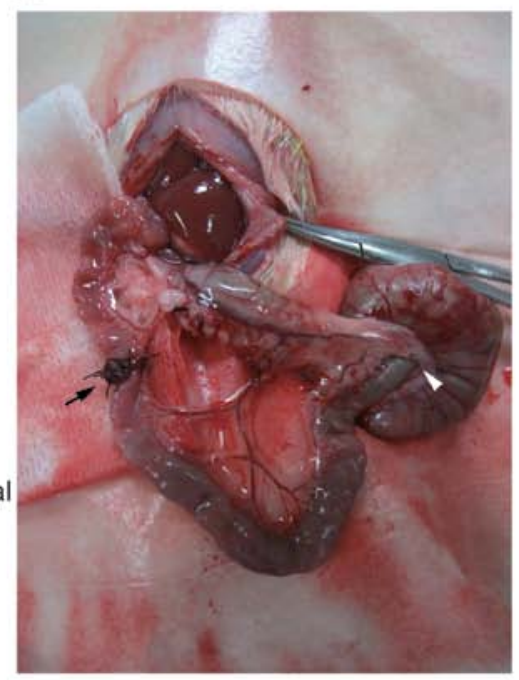

C

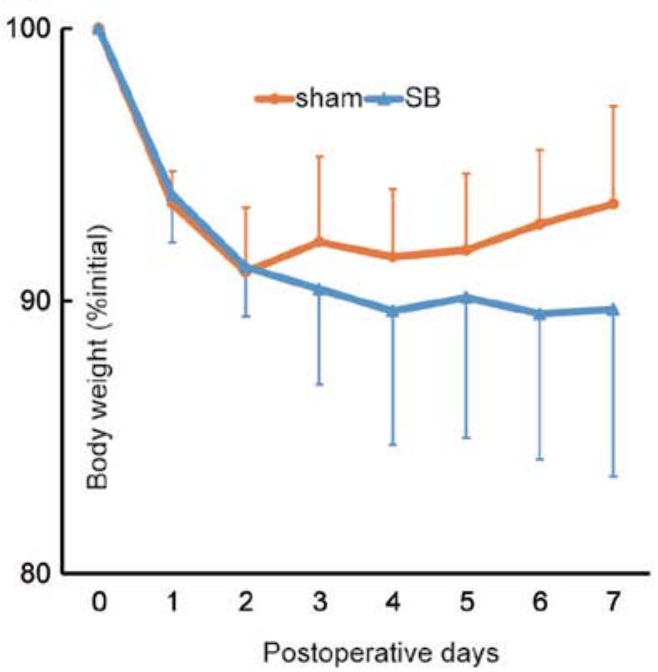

Figure 1. Generation of the rat model of short bowel (SB) syndrome. (A) Schematic representations of the rat model of SB and sham-operated rat model are shown. (B) The anastomosed part of the intestine (arrow) and the ileocecal junction (white arrowhead) are shown. (C) Changes in body weight in rats with SB and sham-operated rats were recorded each day following surgery for 1 week. Data are expressed as the means \pm SD.
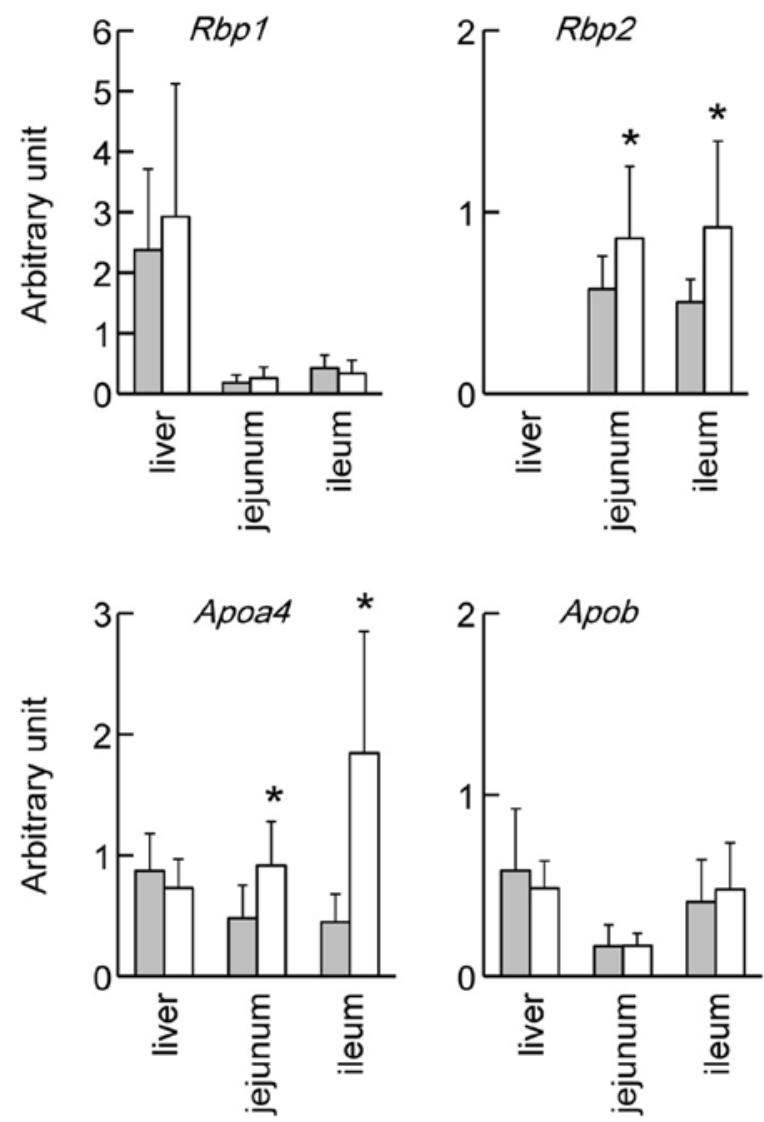
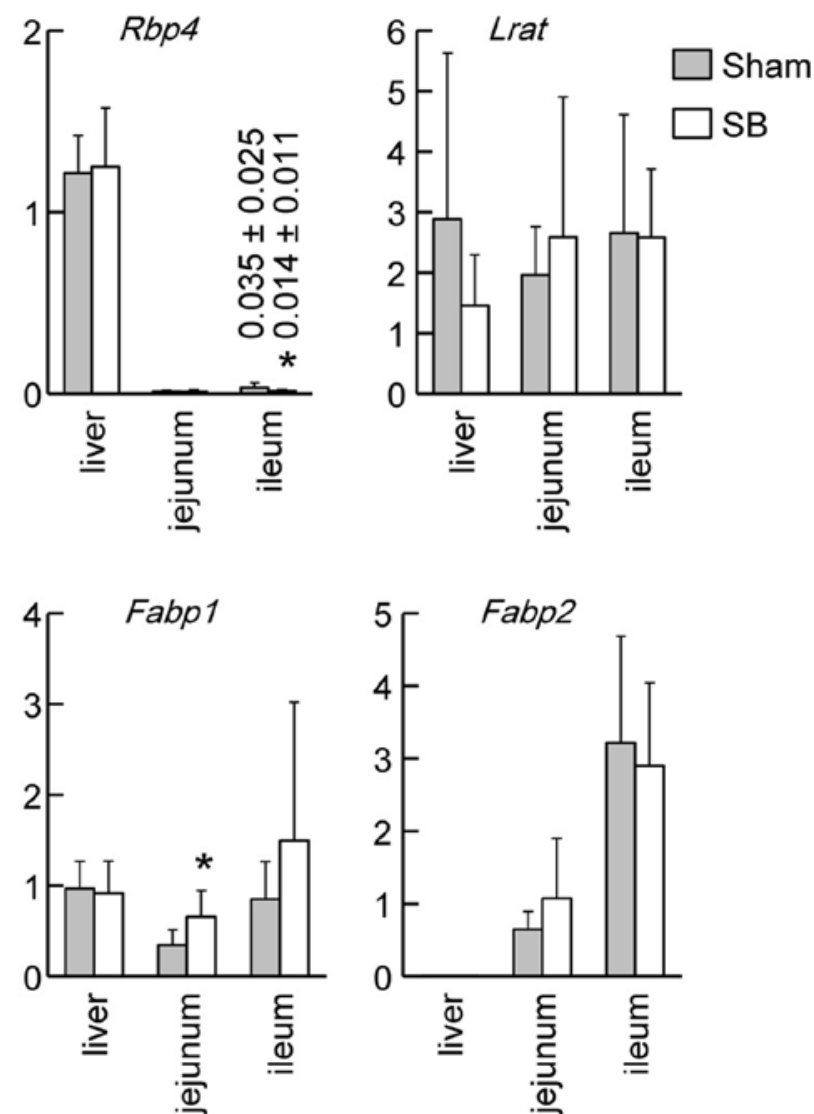

Figure 2. Quantitative analysis of mRNA levels in rats with short bowel (SB) syndrome and sham-operated rats. The mRNA levels of retinol-binding protein $(R b p) 1, R b p 2, R b p 4$, lecithin retinol acyltransferase (Lrat), apolipoprotein A-IV (Apoa4), apolipoprotein B (Apob), fatty acid-binding protein (Fabp)1 and Fabp2 were assessed by RT-qPCR. Data are expressed as the means \pm SD. ${ }^{*} \mathrm{P}<0.05$ was considered to indicate a statistically significant difference.

$(\mathrm{P}<0.05)$. Lrat mRNA coding for retinol-esterifying enzyme was expressed in both the liver and the intestine and did not show any significant differences between the rats with SB and the sham-operated animals. The intestinal mRNA expression levels of Apoa4 in the rats with SB were higher than those in the sham-opearted rats in both the jejuna and the ilea $(\mathrm{P}<0.05)$. 


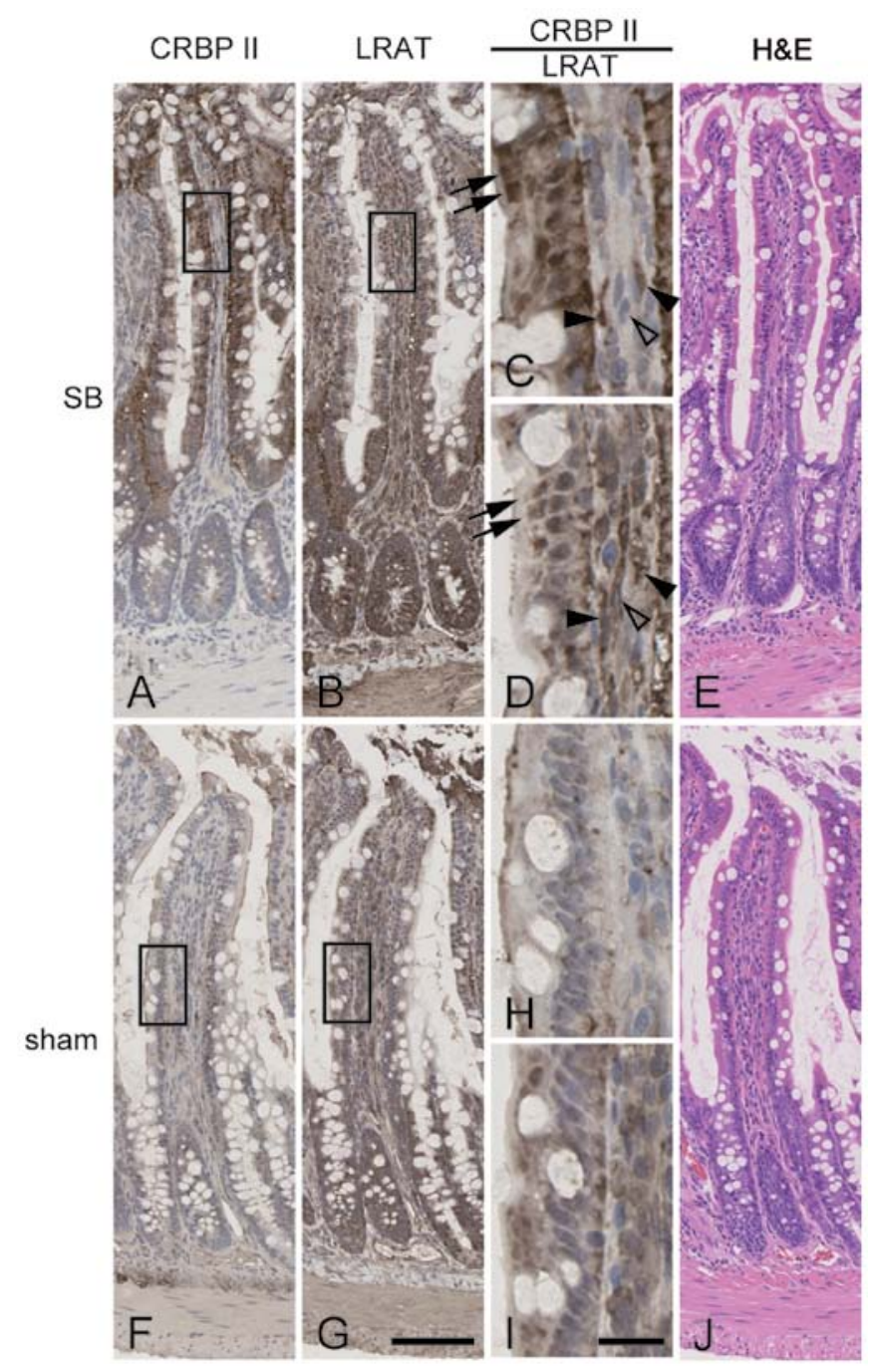

Figure 3. Cellular localizations of cellular retinol-binding protein II (CRBP II) and lecithin retinol acyltransferase (LRAT). Immunohistological staining of serial sections of ileum of rats with short bowel (SB) syndrome (A-D) and that of sham-operated rats (F-I) was performed using antibodies against CRBP II (A, C, F and H) or LRAT (B, D, G and I). High-magnification images of rectangles in (A, B, F and $\mathrm{G})$ are shown in $(\mathrm{C}, \mathrm{D}, \mathrm{H}$ and $\mathrm{I})$, respectively. H\&E-stained sections are shown (E and J). Arrows, absorptive epithelial cells positive for both CRBP II and LRAT. Closed arrowheads, fibroblast-like cells in lamina propria mucosae that were positive for both CRBP II and LRAT. Open arrowheads, fibroblast-like cells positive for LRAT and negative for CRBP II. Scale bar in G is $100 \mu \mathrm{m}$ and applies to (A, B, E, F and J). Scale bar in (I) is $20 \mu \mathrm{m}$ and applies to $(\mathrm{C}, \mathrm{D}$ and $\mathrm{H})$

The mRNA expression of Fabpl in the jejuna of rats with SB was higher than that in the sham-operated rats $(\mathrm{P}<0.05)$.

Co-localization of CRBP II and LRAT in the intestinal absorptive epithelial cells of rats with $S B$. We analyzed the cellular locations of CRBP II and LRAT proteins in the small intestines of rats with SB and sham-operated rats. CRBP II was observed mainly in the absorptive epithelial cells in the ilea of rats with SB (Fig. 3A and C, arrows), while weak staining was observed in the ilea of the sham-operated rats (Fig. 3F and $\mathrm{H}$ ). Immunohistologic staining of LRAT revealed its presence in the absorptive epithelial cells and lamina propria mucosae (Fig. 3B, D, G and I); the staining intensities seemed to be at the same level in the rats with SB and the sham-operated rats.
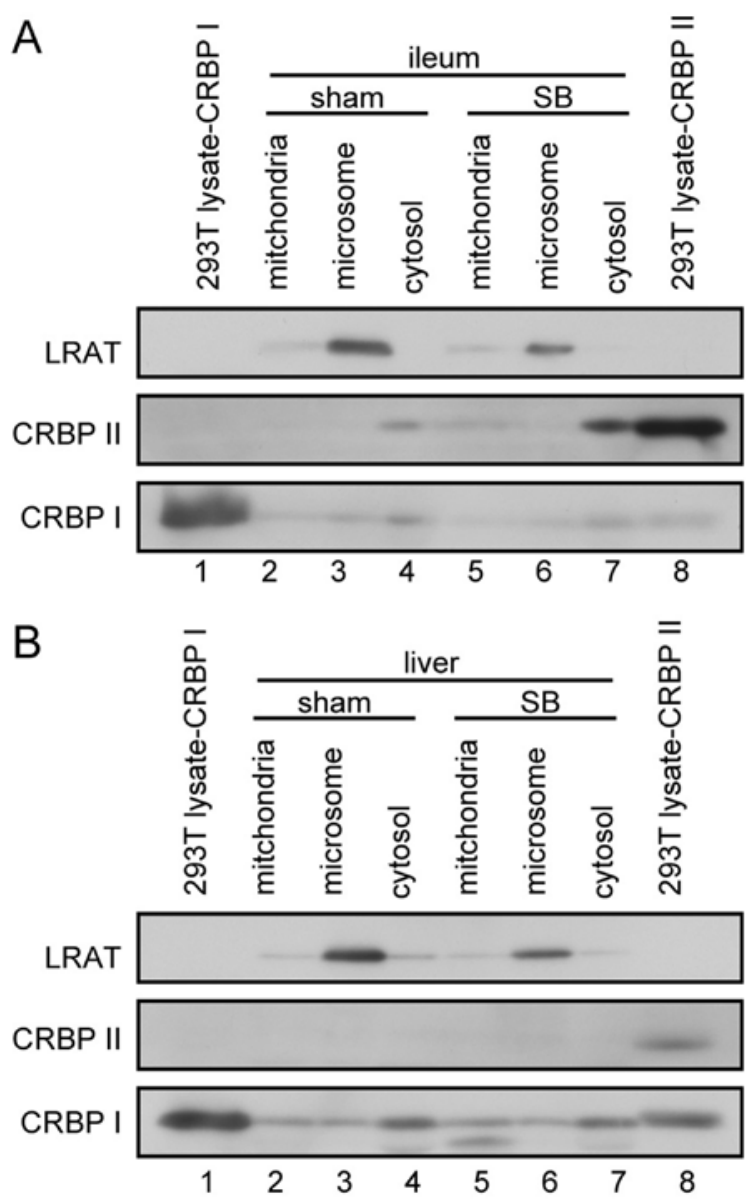

Figure 4. Subcellular localizations of cellular retinol-binding protein (CRBP) II and lecithin retinol acyltransferase (LRAT). Subcellular fractions of tissues from ilea (A) and livers (B) of rats with short bowel (SB) syndrome and sham-operated rats were analyzed by western blotting using antibodies against LRAT, CRBP I and CRBP II.

In the rats with $\mathrm{SB}$, the absorptive epithelial cells were positive for both CRBP II and LRAT staining (Fig. 3C and D, arrows). Some fibroblast-like cells in the lamina propria mucosae seemed to be double-positive (Fig. 3C and D, closed arrowheads) and others to be positive only for LRAT (Fig. 3C and D, open arrowheads). No histological differences were observed between the intestines of the sham-operated rats and the rats with $\mathrm{SB}$, as shown by H\&E staining (Fig. 3E and J).

Subcellular localization of LRAT, CRBP I and CRBP II in the livers and intestines of rats with $S B$ and sham-operated rats. We then analyzed the subcellular distributions of retinoid metabolism-related gene products in the liver and ileum. CRBP II was expressed in the cytosolic fraction of the ileum (Fig. 4A), but not in the liver (Fig. 4B). LRAT was expressed in both the liver and the ileum (Fig. 4), localized in the microsomal fractions. CRBP I was mainly expressed in the liver (Fig. 4B); its expression levels were higher in the cytosolic than in the mitochondrial and microsomal fractions.

Downregulation of retinol and REs in the intestines of rats with $S B$. We then used HPLC to quantify the amounts of retinol and REs in the livers and the intestines of the rats with $\mathrm{SB}$ and the sham-operated rats. The content of REs in the 

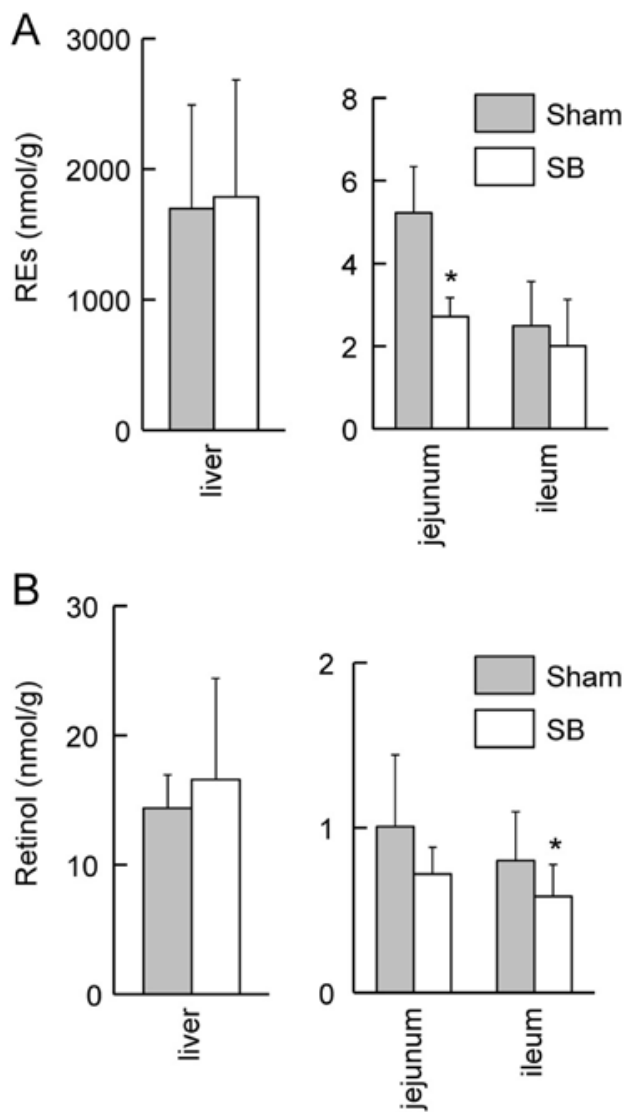

Figure 5. Quantitative analysis of retinol and retinyl esters (REs) in livers and intestines of rats with short bowel (SB) syndrome and sham-operated rats. The REs (A) and retinol (B) in the livers and the intestines of rats with SB and shamoperated rats were quantified by HPLC. Data are expressed as the means \pm SD ${ }^{*} \mathrm{P}<0.05$ was considered to indicate a statistically significant difference.

jejuna of the rats with SB was lower than that of the shamoperated rats (Fig. 5A; $\mathrm{P}<0.05$ ). The retinol content in the ilea of the rats with $\mathrm{SB}$ was lower than that of the sham-operated rats (Fig. 5B; $\mathrm{P}<0.05$ ). There were no significant differences in the contents of retinol and REs in the livers of the rats with SB and the sham-operated rats (Fig. 5).

Upregulation of REs in cultured cells overexpressing CRBP II and LRAT. We wished to determine whether CRBP II affects the amount of REs produced by LRAT. Thus, we quantified REs in HEK293T cells overexpressing CRBP II and/or LRAT. The overexpression of LRAT in the HEK293T cells led to the accumulation of a large amount of REs in the cells within $10 \mathrm{~min}$ of the addition of retinol to the medium $(\mathrm{P}<0.05$; Fig. 6). CRBP II overexpression enhanced the accumulation of REs in the LRAT-transfected HEK293T cells $(\mathrm{P}<0.05)$.

\section{Discussion}

In this study on SB syndrome, we used a rat model of SB to demonstrate that the intestinal mRNA expression levels of $R b p 2$ were significantly higher in the rats with SB than those in the sham-operated rats (Fig. 2). The esterification of vitamin A is regulated by the cooperative actions of LRAT and CRBPs $(18,19)$. In accordance with this, we demonstrated

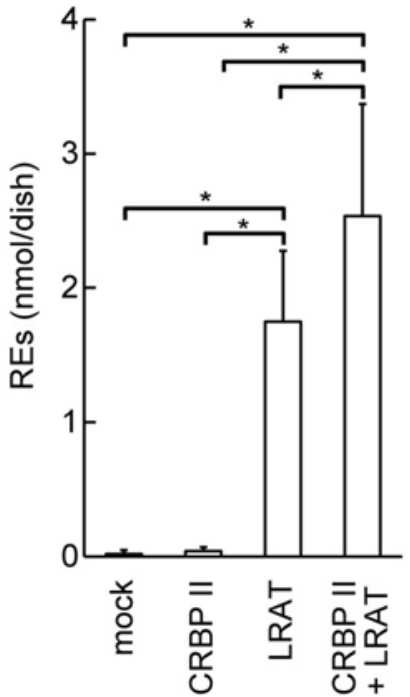

Figure 6. Quantification of retinyl esters (REs) in cultured cells overexpressing cellular retinol-binding protein II (CRBP II) and/or lecithin retinol acyltransferase (LRAT). HEK293T cells were transfected with vectors containing cDNA for CRBP II and/or LRAT. Eighteen hours after transfection, the cells were treated with $10 \mu \mathrm{M}$ retinol and further cultured for $10 \mathrm{~min}$. The cells were collected and REs were quantified by HPLC. Data are expressed as means $\pm \mathrm{SD}$. ${ }^{*} \mathrm{P}<0.05$ was considered to indicate a statistically significant difference.

that the overexpression of CRBP II and LRAT cooperatively increased the amount of REs in the HEK293T cells (Fig. 6). However, we observed a decrease in vitamin A content in the intestines of rats with SB (Fig. 5). The mRNA expression levels of Apoa4 in the intestines of rats with SB were significantly higher than those in the sham-operated animals (Fig. 2), as was previously reported by Rubin et al (20). Apolipoprotein A-IV is a component of chylomicrons (21) in which REs are transported (22). Thus, the upregulation of Apoa 4 mRNA may lead to the enhanced transport of vitamin A from the absorptive epithelial cells to the lymphatic vessels, resulting in the reduction of vitamin A content in the intestines of rats with SB. In spite of the $75 \%$ reduction in the surface area of the intestine, our quantitative analysis revealed no significant differences in the contents of retinol or REs in the livers of rats with SB and the sham-operated rats (Fig. 5), the major storage organ for vitamin A. This may be explained by the functional adaptation of the intestine of rats with SB mediated by the upregulation of Rbp2 and Apoa4 mRNA levels.

It is generally accepted that LRAT is present in the endoplasmic reticulum (ER) (23) and that CRBPs are present in the cytosol (24); our data confirmed these presumptions (Fig. 4). Nevertheless, LRAT and CRBPs likely act cooperatively for vitamin A esterification (25). The $\mathrm{N}$-terminal portion and/or the C-terminal portion of LRAT are inserted into the membranes of the ER, exposing remnant hydrophilic portions to the cytosol $(26,27)$. There, CRBPs probably deliver vitamin A to the cytosolic portion of LRAT.

In immunohistological staining of the small intestines, absorptive epithelial cells were positive for both CRBP II and LRAT (Fig. 3C and D). Their overlapping presence in the rat intestines provides in vivo evidence for the cooperative action of these 2 proteins to increase the absorption of vitamin A. Some 
fibroblast-like cells in the lamina propria mucosae also seemed to be positive for both CRBP II and LRAT. We recently reported that vitamin A was absorbed and stored in the cells of the lamina propria mucosae of rat intestines and transmission electron microscopic analysis revealed that these vitamin A-storing cells in the lamina propria resembled extrahepatic stellate cells (EHSCs) (28). We speculate that the CRBP II- and LRATpositive cells in the lamina propria represent EHSCs. If that is the case, EHSCs express CRBP II, differing from HSCs that express CRBP I. It would be intriguing to determine whether the differential expression of CRBPs in HSCs and EHSCs leads to functional differences between these cells.

SB syndrome is linked to the defective absorption of many types of nutrients, including carbohydrates, fats, amino acids and vitamins. The resultant malnutrition may lead to diseases in various organs. For example, it has been reported that arginine becomes an essential amino acid after massive bowel resection, because citrulline, a precursor of arginine, is synthesized in the small intestine (29). We previously reported that $90 \%$ resection of the rat small intestine caused an insufficiency of citrulline, leading to focal tubulointerstitial fibrosis in the kidney (30). In addition, liver fibrosis has been shown to occur after massive small bowel resection in the neonate piglet SB model (31). The increased esterification and transport of retinol in the absorptive epithelial cells of the intestines of rats with SB, which is suggested in this study, may contribute to prevent such fibrosis, as the suppressive effects of vitamin A on various types of fibrosis are known (32).

In conclusion, our results suggest that the esterification and transport of vitamin $\mathrm{A}$ are enhanced in the absorptive epithelial cells of the intestines of rats with SB through the upregulation of Rbp2 and Apoa 4 mRNA expression.

\section{Acknowledgements}

This study was supported by the JSPS KAKENHI grant nos. 23592623, 25504001 and 23590228.

\section{References}

1. Duro D, Kamin D and Duggan C: Overview of pediatric short bowel syndrome. J Pediatr Gastroenterol Nutr 47 (Suppl 1): S33-S36, 2008.

2. Wall EA: An overview of short bowel syndrome management: adherence, adaptation, and practical recommendations. J Acad Nutr Diet 113: 1200-1208, 2013

3. Shaw D, Gohil K and Basson MD: Intestinal mucosal atrophy and adaptation. World J Gastroenterol 18: 6357-6375, 2012.

4. Wang L, Tang Y, Rubin DC and Levin MS: Chronically administered retinoic acid has trophic effects in the rat small intestine and promotes adaptation in a resection model of short bowel syndrome. Am J Physiol Gastrointest Liver Physiol 292: G1559-G1569, 2007.

5. Harrison EH: Mechanisms of digestion and absorption of dietary vitamin A. Annu Rev Nutr 25: 87-103, 2005.

6. Blomhoff R and Blomhoff HK: Overview of retinoid metabolism and function. J Neurobiol 66: 606-630, 2006.

7. Wake K: 'Sternzellen' in the liver: perisinusoidal cells with special reference to storage of vitamin A. Am J Anat 132: 429-462, 1971.

8. Senoo H: Structure and function of hepatic stellate cells. Med Electron Microsc 37: 3-15, 2004.

9. Newcomer ME: Retinoid-binding proteins: structural determinants important for function. FASEB J 9: 229-239, 1995.

10. Flower DR, North AC and Sansom CE: The lipocalin protein family: structural and sequence overview. Biochim Biophys Acta 1482: 9-24, 2000.
11. Sherman DR, Lloyd RS and Chytil F: Rat cellular retinol-binding protein: cDNA sequence and rapid retinol-dependent accumulation of mRNA. Proc Natl Acad Sci USA 84: 3209-3213, 1987.

12. Colantuoni V, Cortese R, Nilsson M, Lundvall J, Bavik CO, Eriksson U, Peterson PA and Sundelin J: Cloning and sequencing of a full length cDNA corresponding to human cellular retinolbinding protein. Biochem Biophys Res Commun 130: 431-439, 1985.

13. Li E, Demmer LA, Sweetser DA, Ong DE and Gordon JI: Rat cellular retinol-binding protein II: use of a cloned cDNA to define its primary structure, tissue-specific expression, and developmental regulation. Proc Natl Acad Sci USA 83: 5779-5783, 1986.

14. E X, Zhang L, Lu J, Tso P, Blaner WS, Levin MS and Li E: Increased neonatal mortality in mice lacking cellular retinolbinding protein II. J Biol Chem 277: 36617-36623, 2002.

15. Takase S, Goda T and Shinohara H: Adaptive changes of intestinal cellular retinol-binding protein, type II following jejunum-bypass operation in the rat. Biochim Biophys Acta 1156: 223-231, 1993.

16. Dodson BD, Wang JL, Swietlicki EA, Rubin DC and Levin MS: Analysis of cloned cDNAs differentially expressed in adapting remnant small intestine after partial resection. Am J Physiol 271: G347-G356, 1996.

17. Wang JL, Swartz-Basile DA, Rubin DC and Levin MS: Retinoic acid stimulates early cellular proliferation in the adapting remnant rat small intestine after partial resection. J Nutr 127: 1297-1303, 1997.

18. Ong DE, Kakkad B and MacDonald PN: Acyl-CoA-independent esterification of retinol bound to cellular retinol-binding protein (type II) by microsomes from rat small intestine. J Biol Chem 262: 2729-2736, 1987.

19. Yost RW, Harrison EH and Ross AC: Esterification by rat liver microsomes of retinol bound to cellular retinol-binding protein. J Biol Chem 263: 18693-18701, 1988.

20. Rubin DC, Swietlicki EA, Wang JL, Dodson BD and Levin MS: Enterocytic gene expression in intestinal adaptation: evidence for a specific cellular response. Am J Physiol 270: G143-G152, 1996.

21. Green PH, Glickman RM, Riley JW and Quinet E: Human apolipoprotein A-IV. Intestinal origin and distribution in plasma. J Clin Invest 65: 911-919, 1980.

22. Goodman DW, Huang HS and Shiratori T: Tissue distribution and metabolism of newly absorbed vitamin A in the rat. J Lipid Res 6: 390-396, 1965.

23. Ruiz A, Winston A, Lim YH, Gilbert BA, Rando RR and Bok D: Molecular and biochemical characterization of lecithin retinol acyltransferase. J Biol Chem 274: 3834-3841, 1999.

24. Ong DE and Chytil F: Cellular retinol-binding protein from rat liver. Purification and characterization. J Biol Chem 253: 828-832, 1978.

25. Napoli JL: Interactions of retinoid binding proteins and enzymes in retinoid metabolism. Biochim Biophys Acta 1440: 139-162, 1999.

26. Bok D, Ruiz A, Yaron O, Jahng WJ, Ray A, Xue L and Rando RR: Purification and characterization of a transmembrane domaindeleted form of lecithin retinol acyltransferase. Biochemistry 42: 6090-6098, 2003.

27. Moise AR, Golczak M, Imanishi Y and Palczewski K: Topology and membrane association of lecithin:retinol acyltransferase. J Biol Chem 282: 2081-2090, 2007.

28. Senoo H, Mezaki Y, Morii M, Hebiguchi T, Miura M and Imai K: Uptake and storage of vitamin A as lipid droplets in the cytoplasm of cells in the lamina propria mucosae of the rat intestine. Cell Biol Int 37: 1171-1180, 2013.

29. Wakabayashi Y, Yamada E, Yoshida T and Takahashi H: Arginine becomes an essential amino acid after massive resection of rat small intestine. J Biol Chem 269: 32667-32671, 1994.

30. Hebiguchi T, Kato T, Yoshino H, Mizuno M, Wakui H, Komatsuda A and Imai H: Extremely short small bowel induces focal tubulointerstitial fibrosis. J Pediatr Gastroenterol Nutr 32: 586-592, 2001.

31. Taguchi S, Masumoto K, Yamanouchi T and Suita S: Decrease in hepatic circulation induces hepatic fibrosis in a neonatal piglet model with short bowel syndrome. J Pediatr Surg 40: 1592-1597, 2005.

32. Senoo H and Wake K: Suppression of experimental hepatic fibrosis by administration of vitamin A. Lab Invest 52: 182-194, 1985. 